\title{
Single and nested polymerase chain reaction assays for the detection of Microsporidium seriolae (Microspora), the causative agent of 'Beko' disease in yellowtail Seriola quinqueradiata
}

\author{
Andrew S. Bell ${ }^{1, *}$, Hiroshi Yokoyama ${ }^{2}$, Takashi Aoki ${ }^{1}$, Makoto Takahashi ${ }^{3}$, \\ Keigo Maruyama ${ }^{3}$ \\ 'Department of Aquatic Bioscience, Tokyo University of Fisheries, Konan 4-5-7, Minato-ku, Tokyo 108, Japan \\ ${ }^{2}$ Department of Aquatic Bioscience, Graduate School of Agricultural and Life Sciences, The University of Tokyo, Yayoi 1-1-1, \\ Bunkyo-ku, Tokyo 113, Japan \\ ${ }^{3}$ Goto Station of Japan Sea-Farming Association, Arakawa, Tamanoura-cho, Minamimatsuura-gun, Nagasaki 853-05, Japan
}

\begin{abstract}
Single and nested polymerase chain reaction (PCR) assays were developed for the detection of the microsporidian parasite Microsporidium seriolae, which is responsible for emaciation and even death in farmed Japanese yellowtall. Extremely high rDNA identities exist between this parasite and other members of the as yet unclassified genus, necessitating the design of generic, rather than species-specific primer sets. The nested PCR was several orders of magnitude more sensitive than the standard single PCRs, with visible target product amplified from as little as $0.01 \mathrm{pg}$ of parasite DNA (equivalent to that extracted from a single spore). The specificity of the assays was tested against a range of potential host fishes and 6 other microsporidians infecting either fish or the musculature of their hosts. Single PCRs were found to be specific to the target genus, but the nested PCR replicated rDNA from several different microsporidian genera, limiting its utility. This study highlights problems associated with the use of the rRNA gene for PCR assays of certain microsporidians, but nevertheless provides a rapid and sensitive means for the detection of pre-spore forms not possible by current staining methods. Consequently, these assays may be employed for further studies on the portals of entry, migration to the musculature and transmission of this economically important pathogen.
\end{abstract}

KEY WORDS: Microsporidium seriolae - Microsporidia - Ribosomal DNA P Polymerase chain reaction Fish diseases

\section{INTRODUCTION}

Microsporidium seriolae is an obligate intra-cellular protist parasite infecting the musculature of yellowtail Seriola quinqueradiata. This microsporidian was first reported from the Kyushu area of Japan by Egusa in 1982; infections appeared as elongate white masses in longitudinal sections, with each mass bound by a hostproduced fibrous membrane. Heavy infections caused

- Present address: The Institute of Aquaculture, University of Stirling, Stirling FK9 4LA, Scotland, UK.

E-mail: asb2@stir.ac.uk liquefaction of muscle fibres around the masses and resulted in the characteristic concave body surface associated with 'Beko' disease. The causative pathogen could not be classified into any established genus and Egusa (1982) placed it provisionally into the collective genus Microsporidium Balbiani, 1884, as M. seriolae. This parasite has continued to cause high mortalities among cultured yellowtail and severely affects seed production in the Kyushu region (Yokoyama et al. 1996, Sano et al. 1998).

Screening for Microsporidium seriolae infection is currently performed on smear preparations, using the sensitive fluorochrome stain Uvitex 2B (see DeGiro- 
lami et al. 1995, Yokoyama et al. 1996). However, this stain binds specifically to chitin, limiting detection to mature spores. Vossbrinck et al. (1993) described a set of primers (designated $530 \mathrm{f}$ and 580r due to their relative positions in Escherichia coli rDNAj that recognise highly conserved sequences within the IRNA gene of most organisms, including microsporidians. The resultant DNA amplified by the polymerase chain reaction (PCR) extends from within the small subunit (SSU), through the internal transcribed spacer (ITS) region and into the large subunit (LSU). The authors found that highly variable, moderately variable and highly conserved regions were present in the approximately $1350 \mathrm{bp}$ sequences thus obtained for Encephalitozoon cuniculi, E. hellem, Vairimorpha necatrix, V. lymnatria and Ichthyosporidium intestinalis. Subsequentiy, Zhu et al. (1994) recorded similar degrees of conservation and variation in the equivalent rDNA sequences of Enterocytozoon bieneusi, Encephalitozoon (= Septata) intestinalis and Ameson michaelis. Indeed, speciesspecific rDNA primer sets have since been developed for use in PCR assays. These have largely targeted the SSU of species responsible for microsporidiosis in human immunodeficiency virus (HIV)-infected patients (inter alia Schuitema et al. 1993, Visvesvara et al. 1994, De Groote et al. 1995, David et al. 1996), although Barlough et al. (1995) used 'nested' SSU primers to detect Nucleospora (=Enterocytozoon) salmonis infections in chinook salmon Oncorhynchus tshawytscha and Kent et al. (1996) employed primers external to the ITS region (in the SSU and LSU) for the same purpose. More recently, Docker et al. (1997) utilised the variable ITS region and the 5 end of the rDNA LSU for their single primer set to detect Loma salmonae, also in chinook salmon.

In their study of microsporidian phylogeny, Bell et al. (unpubl. data) gathered rDNA (530f-580r) sequence data for Microsporidium seriolae, a Microsporidium sp. infecting the musculature of red sea bream Pagrus major (see Egusa et al. 1988) and an unidentified microsporidian described by Abela et al. (1996) from gilthead sea bream. These sequence data revealed the 3 unclassified microsporidians to be extremely closely interrelated, demonstrating sequence identities in excess of $98 \%$ (distance data <0.019) and they were considered to, at least, comprise members of a common genus. Such sequence homologies, even within the highly variable ITS region, preclude the rRNA gene as a target for $M$. seriolae-specific primer sets. Nevertheless, this gene may still be of considerable utility for monitoring infections and studying the biology of this parasite. Sequence data is extremely limited for other microsporidian genes, hindering effective primer design, and collectively the rDNA of these Microsporidium spp. differ markedly from all other micro- sporidia studied thus far. Consequently, the current study aimed to develop generic rDNA assays with a high degree of specificity and great sensitivity, to enable the early detection of $M$. seriolae infections. Such assays could also be utilised for screening red sea bream and gilthead sea bream for their closely related microsporidian pathogens. In addition, a PCR assay would enable the screening of these fishes' tissues and body fluids to determine the parasites' portals of entry into the host and the subsequent migration route to the host's musculature, which are currently unknown.

\section{MATERIALS AND METHODS}

Sources of microsporidian spores. Infected muscle fibres containing spores of 3 microsporidians, Microsporidium seriolae, Microsporidium sp. of Egusa et al. (1988) and the unidentified microsporidian of Abela et al. (1996), were excised from the musculature of farmed Japanese yellowtail, Japanese red sea bream and Maltese gilthead bream, respectively. Spores of 2 further unidentified species were obtained from the musculature of the shrimp Metapenaeus joineri and from an unidentified myxosporean infecting the intestinal epithelium of tiger puffer Takifugu ruripes, both from Japanese fisheries. Pleistophora mirandellae spores were obtained from the gonads of Finnish roach Rutilus rutilus, Glugea plecoglossi from xenomas in the viscera of Japanese ayu Plecoglossus altivelis, a Glugea sp. from xenomas on Scottish sticklebacks Gasterosteus aculeatus, and Heterosporis anguillarum from the musculature of the Japanese eel Anguilla japonica.

Spore isolation and DNA extraction. Spores were isolated from host tissues and purified by washing, sieving and centrifugation through a discontinuous Percoll gradient. Purified spores were pelleted (approx. $20 \mu \mathrm{l}$ in volume), washed in high concentration urea buffer (TNES-urea: $10 \mathrm{mM}$ Tris-HCl, pH 7.5; $125 \mathrm{mM} \mathrm{NaCl}$; $10 \mathrm{mM}$ EDTA; $0.5 \% \mathrm{SDS}_{4} \mathrm{M}$ urea), resuspended in $0.5 \mathrm{ml}$ of the same medium and vortexed (in a manner to maximise shearing directions) for $1 \mathrm{~min}$ with $0.4 \mathrm{~g}$ of $0.5 \mathrm{~mm}$ silica beads to facilitate the disruption of mature spore walls. After centrifugation at $1000 \times g$ for $3 \mathrm{~min}$ the supernatant was removed, its volume adjusted to $0.5 \mathrm{ml}$, proteinase $\mathrm{K}$ added to a concentration of $100 \mu \mathrm{g}$ $\mathrm{ml}^{-1}$ and digestion allowed to occur overnight in a $37^{\circ} \mathrm{C}$ tilting waterbath. DNA was subsequently extracted with Tris-saturated phenol, phenol:chloroform:isoamylalcohol (25:24:1) and diethyl ether, then precipitated at $-80^{\circ} \mathrm{C}$ with $2.5 \times$ volume of $95 \%$ cold ethanol and $0.1 \times$ volume of sodium acetate, and finally resuspended in sterilised MilliQ water. DNA concentrations and purities were checked on a Pharmacia GeneQuant 
RNA/DNA calculator and DNA quality observed in an ethidium bromide-stained $1 \%$ agarose gel.

Cloning and sequencing of microsporidian species. The targeted DNA was amplified using the PCR primers described by Vossbrinck et al. (1993): forward primer 530f (5'-GTGCCATCCAGCCGCGG-3'), reverse primer 580r (5'-GGTCCGTGTTTCAAGACGG-3'). Each $50 \mu \mathrm{l}$ reaction comprised $25 \mathrm{pM}$ of each primer, $0.2 \mathrm{mM}$ dNTP, $1.5 \mathrm{mM} \mathrm{MgCl}, 50 \mathrm{mM} \mathrm{KCl}, 10 \mathrm{mM}$ Tris-HCl (pH 8.3), 0.1\% Triton $X-100,1.2$ units rTaq DNA polymerase (Toyobo Co., Ltd, Japan) and $100 \mathrm{ng}$ of template DNA. Reactions were overlaid with sterile liquid paraffin and run on an ASTEC PC-700 thermocycler. After an initial denaturation at $95^{\circ} \mathrm{C}$ for $5 \mathrm{~min}$, samples were subjected to 30 cycles of amplification (denaturation at $95^{\circ} \mathrm{C}$ for $30 \mathrm{~s}$, primer annealing at $43^{\circ} \mathrm{C}$ for $30 \mathrm{~s}$, and extension at $72^{\circ} \mathrm{C}$ for $1 \mathrm{~min}$ ), followed by a $10 \mathrm{~min}$ terminal extension at $72^{\circ} \mathrm{C}$. The PCR product obtained was visualised in an ethidium bromide-stained $1 \%$ agarose gel, the DNA band excised and purified using the UltraClean ${ }^{T M} 15$ kit (Mo Bio Laboratories, Inc., Solana Beach, CA, USA). Target DNA was cloned using the either the pMOSBlue Blunt Ended Cloning Kit (Amersham ${ }^{\text {TM }}$ International plc., Bucks., England), the pT7Blue(R) Perfectly Blunt Cloning Kit (Novagen Inc., Madison, WI, USA), or pGEM ${ }^{R}-T$ Easy Vector Systems (Promega Corporation, Madison, WI, USA), in conjunction with competent Escherichia coli strain JM 109. Sequencing across the insert was performed with a Thermo Sequenase fluorescent labelled primer kit with 7-deaza-dGTP (Amersham ${ }^{\mathrm{TM}}$ ). Determined sequences were based upon both sense and anti-sense strands of a minimum of 3 clones. Sequence identities and alignments were investigated using the Genetyx and ATSQ 3.0 programs for the AppleMac, respectively.

Development of PCR primer sets. The consensus sequences obtained for Microsporidium seriolae (8 clones), the Microsporidium sp. from red sea bream (6 clones) and the unknown microsporidian from gilthead sea bream (5 clones) were aligned and compared with those of the 5 other microsporidians sequenced in the current study, as well as with all other comparable microsporidian data available in GenBank. Potential M. seriolae sense and anti-sense primer sequences were chosen from areas of maximum non-identity with other microsporidians. Suitable pairs were then tested in both single and nested PCRs with the genomic DNA of the 9 microsporidians available to the current study and against 5 fish species, including yellowtail and gilthead sea bream.
Primers utilised and details of PCR conditions which differed from those employed with the 530f and 580r primer set are provided in Table 1. For nested PCRs, $1 \mu \mathrm{l}$ of the first PCR (Round I) product was used as template in the second PCR (Round II) reaction mixture. Appropriate internal controls were included in each PCR and all samples were run in duplicate

Sensitivities and specificities of the PCRs. Sensitivities of the single and nested PCRs were determined using previously extracted Microsporidium seriolae genomic DNA of a known concentration which was serially diluted with DNA from a control fish (uninfected yellowtail); total DNA within each $50 \mu$ l reaction was maintained at $100 \mathrm{ng}$. Sensitivity tests were also performed on serially diluted DNA extracted from 100 spores; i.e. DNA from 100 spores resuspended in $10 \mu \mathrm{l}$ of MilliQ filtered water $\equiv 10$ spores $\mu^{-1}$.

PCR specificities were tested against the genomic DNAs of the microsporidian species listed above and 5 potential piscine host species: yellowtail, gilthead sea bream, koi carp Cyprinus carpio, Atlantic salmon Salmo salar and coho salmon Oncorhynchus kisutch.

Radioactive Southern blotting for preliminary confirmation of PCR product identity. PCR products were Southern blotted onto Hybond ${ }^{T M}-N^{+}$positively charged nylon membranes (Amersham ${ }^{\mathrm{TM}}$ ) and hybridisation performed, according to standard conditions, with the double stranded DNA probe MS-LSU. This probe, constituting $239 \mathrm{bp}$ of the 5 ' end of the Microsporidium seriolae rDNA LSU, was obtained from previously sequenced plasmid inserts and labelled with $\mathrm{dCTP}^{32}$ using the Takara Random Primer DNA Labelling Kit (Takara Biomedicals, Japan). Ultimate verification of product identities was performed by the cloning and sequencing of randomly selected bands.

Treatment of tissue samples to be screened for Microsporidium seriolae infection. In a preliminary experiment to test the ability of the PCR assay on field samples, yellowtail were bred and reared in landbased tanks at the Goto Research Station of the Japan Sea-Farming Association and either transferred to sea netpens (experimental group) or maintained within the

Table 1. Oligonucleotide primers used for Microsporidium seriolae polymerase chain reactions (PCRs)

\begin{tabular}{|c|c|c|c|c|}
\hline Primer sets & Location & $5^{\prime} \rightarrow 3^{\prime}$ sequence & Insert size & PCR conditions \\
\hline \multicolumn{5}{|c|}{ Outer primers } \\
\hline MS-F1 & SSU & CACCTGTCTGCAATGCGGG & 1216 or & \multirow{2}{*}{$\begin{array}{l}\text { Annealing } \\
\text { temp. } 59^{\circ} \mathrm{C}\end{array}$} \\
\hline MS-R1 & LSU & GGTTGTTTGGCCGTACGGGG & $1205 b p^{a}$ & \\
\hline \multicolumn{5}{|c|}{ Inner primers } \\
\hline MS-F2 & SSU & GGTCGCAGCAGGAGCTTTC & 560 or & \multirow{2}{*}{$\begin{array}{l}\text { Annealing } \\
\text { temp. } 59^{\circ} \mathrm{C}\end{array}$} \\
\hline MS-R2 & LSU & CTTCCGGCGTATCTTTAGTC & $549 \mathrm{bp}^{a}$ & \\
\hline
\end{tabular}


land-based tanks fed with sand-filtered seawater (control group). Twenty fish were randomly sampled from each group at $40 \mathrm{~d}$ post-transfer. Fish were filleted and visible signs of infection noted. A $50 \mathrm{mg}$ sample of musculature was collected from each fish, homogenised (using separate, previously autoclaved, plastic homogenisers) with $500 \mu$ of TNES-urea in a microfuge tube (rendering the DNA stable at room temperature) and transported to Tokyo University of Fisheries, where the DNA was extracted as described earlier. A further $1 \mathrm{~g}$ of muscle from each fish was frozen and then taken to Tokyo University on ice. Here the samples were homogenised, sieved, pelleted, washed, repelleted and used to make smear preparations which were then stained with Uvitex $2 \mathrm{~B}$ and examined by fluorescent microscopy.

\section{RESULTS}

\section{Microsporidium seriolae rDNA sequence}

The 530f and 580r PCR primer set yielded a single product when viewed in ethidium bromide-stained agarose gels. However, from the sequencing of 8 clones containing this insert it was apparent that 2 forms of the rRNA gene exist for this microsporidian. One form was found to be $1463 \mathrm{bp}$ in length ( 3 clones) and the other 1452 bp (5 clones), the latter having an 11 bp (ATACATATACG) deletion within the ITS region (Bell, Aoki \& Yokoyama unpubl. data). The Microsporidium sp. similarly possessed 2 forms of the gene (1464 and $1453 \mathrm{bp}$ ), although only the shorter form was recorded from the unidentified microsporidian from gilthead sea bream (1454 bp).

\section{PCR primer design}

Four forward ( 3 within the SSU and 1 within the ITS region) and 3 reverse primers (all within the LSU) were designed and tested for specificity and sensitivity. Of these the most reliable pairs were found to be those listed in Table 1 as MS-F1, MS-R1, MS-F2 and MS-R2. Empirical testing revealed that annealing temperatures of typically 1 to $2^{\circ} \mathrm{C}$ below the primer melting temperature $(T m)$ were optimal. Highly stringent PCR conditions with $\mathrm{MgCl}_{2}$ concentrations $<1 \mathrm{mM}$ and $12.5 \mathrm{pM}$ of each primer improved specificities, but compromised sensitivity (data not shown). Annealing temperatures of above the empirically tested optimum, hot start PCR, touchdown PCR, or the use of Ex Taq DNA polymerase rather than the less exacting rTaq were all found to have minimal effects on PCR stringency (data not shown).

\section{Detection threshold of the PCR}

The detection threshold of the PCRs, using either the external primer set ( $F 1$ and R1: 1216 or $1205 \mathrm{bp}$; see Fig. 1, top) or the internal primer set (F2 and R2: 560 or $549 \mathrm{bp}$; not shown) singularly were between 1 and $10 \mathrm{pg}$ of template DNA for 30 PCR cycles. Increasing the number of PCR cycles to 35 for the internal set typically improved sensitivity to $0.1 \mathrm{pg}$ of DNA, but resulted in an additional spurious product (approximately $200 \mathrm{bp}$ ) being amplified from host tissues during screening. The nested PCR was several orders of magnitude more sensitive than the standard single PCRs, with visible target product amplified from between 0.01 and $0.1 \mathrm{pg}$ of template DNA (Fig. 1, bottom). Assuming that all DNA was extracted from spores, the nested PCR was found to be able to detect DNA originating from a single spore per reaction mixture, which presumably approximates to $0.01-0.1 \mathrm{pg}$.

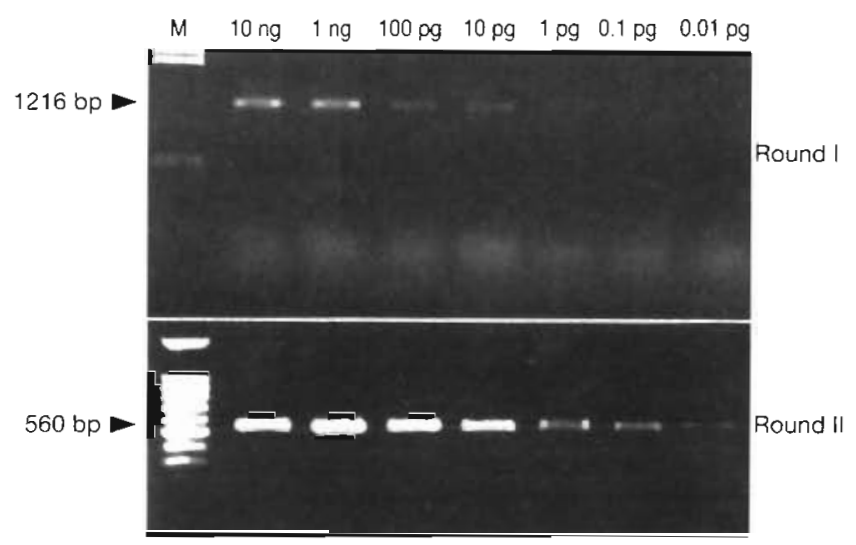

Fig. 1. Detection threshold of the nested PCR for Microsporidium seriolae DNA. Total DNA in each reaction mixture was maintained at $100 \mathrm{ng}$ by the addition of uninfected yellowtail DNA. Arrowheads indicate the position of the $1216 \mathrm{bp}$ product resulting from the single PCR (Round I; top) and the 560 bp product of the nested PCR (Round II; bottom). M: Lane markers; top, lambda phage-Hind III digest; bottom, $100 \mathrm{bp}$ ladder

\section{Specificity of the PCR}

Fig. 2 (top) shows that when used singularly the external primer set appeared, at the level visually detectable in ethidium bromide-stained agarose gels, to amplify genomic DNA of only Microsporidium seriolae, the Microsporidium sp. excised from red sea bream, and that of the unidentified microsporidian from gilthead sea bream (the targeted species). The same specificity was also recorded for the internal primer set (not shown). However, the non-specific results obtained with the nested PCR (Fig. 2, bottom) 


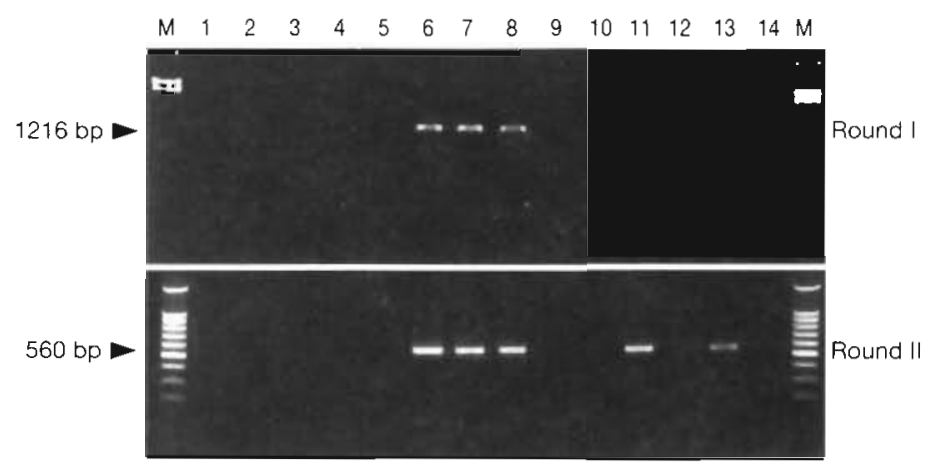

Fig. 2. Specificity of the nested PCR using DNA from 5 potential fish hosts and various microsporidian species which are either parasites of fish and/or of musculature. Numbered lanes: 1 , yellowtail; 2 , gilthead sea bream; 3 , koi carp; 4 , coho salmon; 5, Atlantic salmon; 6, Microsporidium seriolae; 7, Microsporidium sp. (red sea bream); 8, unidentified microsporidian species (gilthead sea bream); 9, Glugea plecoglossi; 10, Glugea sp. (3-spined stickleback); 11, unidentified microsporidian species (metapenaeid shrimp); 12, Heterosporis anguillarum; 13, Pleistophora mirandellae; 14, unidentified microsporidian species (myxosporean). Arrowheads indicate the position of the $1216 \mathrm{bp}$ single PCR (Round I, top) and 560 bp nested PCR (Round II, bottom) products. M: Lane markers; top, lambda phage-Hind III digest; bottom, $100 \mathrm{bp}$ ladder

indicated that some amplification of microsporidian DNA from certain non-target species must also occur during PCR Round I and that this is further amplified during Round II. Genomic DNA from potential piscine hosts was never amplified by the PCRs under the conditions specified.

A primer set (not shown) which incorporated a forward primer targeted to the 3 ' end of the ITS region and produced a $257 \mathrm{bp}$ amplicon demonstrated extremely poor specificity, often amplifying a similar sized product from target and non-target microsporidian species, as well as from host DNA.

\section{Screening of yellowtail for Microsporidium seriolae infection}

The results of a preliminary study into the utility of these PCR assays for the screening of Microsporidium seriolae infections are provided in Table 2. This table only includes the results obtained from fish exposed to the infectious agent; fish from the control group tested negative for infection by all examination methods. Fig. 3A shows PCR products obtained in the screening of 6 experimental fish and Fig. 3B the results of the subsequent radio-labelled Southern hybridisations. Four such bands from apparently infected fish were excised from the agarose gel, and the DNA purified
Table 2. Comparison of results obtained by visual inspection, Uvitex $2 B$ staining and $P C R$ assays for the screening of yellowtail musculature for infection with Microspondium seriolae

\begin{tabular}{|c|c|c|c|c|}
\hline Fish no. & $\begin{array}{c}\text { Visual } \\
\text { inspection }\end{array}$ & $\begin{array}{l}\text { Uvitex } 2 \mathrm{~B} \\
\text { staining }\end{array}$ & $\begin{array}{c}\text { Single PCR } \\
\quad(\mathrm{F} 1 \& \mathrm{R} 1)\end{array}$ & $\begin{array}{l}\text { Nested } \\
\text { PCR }\end{array}$ \\
\hline 1 & - & + & + & + \\
\hline 2 & - & - & - & + \\
\hline 3 & - & - & - & - \\
\hline 4 & - & - & - & - \\
\hline 5 & - & - & - & - \\
\hline 6 & - & + & - & - \\
\hline 7 & - & + & - & - \\
\hline 8 & - & - & - & - \\
\hline 9 & - & - & - & - \\
\hline 10 & - & - & - & - \\
\hline 11 & - & - & - & - \\
\hline 12 & - & - & - & - \\
\hline 13 & - & - & - & - \\
\hline 14 & - & - & - & + \\
\hline 15 & - & + & - & + \\
\hline 16 & - & + & + & + \\
\hline 17 & - & + & + & + \\
\hline 18 & - & - & + & + \\
\hline 19 & - & - & + & + \\
\hline 20 & - & - & + & + \\
\hline$\%$ infected & 5 & 30 & 30 & 45 \\
\hline
\end{tabular}

and cloned. Sequencing of these inserts revealed the products to be the targeted region of the $M$. seriolae rRNA gene.

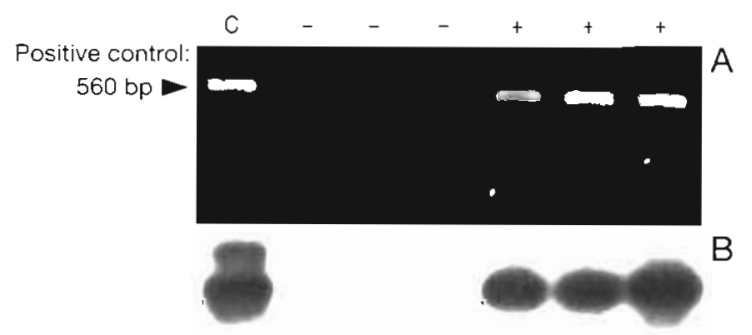

Fig. 3. (A) Ethidium bromide-stained agarose gel of Microsporidium seriolae nested PCR products using DNA extracted from the musculature of 6 yellowtail exposed to infection; (+) positive testing fish, (-) negative testing fish. (B) Southern blot of amplified DNA in (A) hybridised with a radiolabeled 239 bp DNA probe. Arrowhead indicates the position of the $560 \mathrm{bp}$ nested PCR (Round II) product. Lane headed C shows positive control: DNA extracted from $M$. seriolae spores

\section{DISCUSSION}

Levels of rDNA identity (530f-580r region) within certain fish-infecting genera often exceed $98 \%$ (Bell et al. unpubl. data), far higher than those values recorded for species isolated from immune-compromised individuals, for which the majority of species-specific 
rDNA primer sets have so far been developed (for a review see Weiss \& Vossbrinck 1998). These homologies make the design of reliable, species-specific, rDNA-targeted, PCR assays for genera such as Pleistophora Gurley, 1893, Glugea ThClohan, 1892 and the unclassified genus comprising the Microsporidium spp. of the current study impossible.

The present study developed 2 separate, putatively genus-specific, PCR primer sets for Microsporidium seriolae which were able to identify $1 \mathrm{pg}$ of microsporidian DNA in a $50 \mu \mathrm{l}$ reaction volume. Using these 2 sets as a nested assay increased the sensitivity by 2 to 3 orders of magnitude, providing a typical detection threshold of $0.01 \mathrm{pg}$ of DNA, equivalent to less than that obtained from a single $M$. seriolae spore. However, the nested assay proved to be non-specific, even among a test group of just 6 other microsporidians from different genera; the genomic DNAs of Pleistophora mirandellae from xenomas in roach ovaries and an unidentified species infecting the musculature of shrimp yielded PCR products of the anticipated size for these species (see Fig. 2). These bands also hybridised with the $239 \mathrm{bp}$ (non species-specific) rDNA probe, strongly suggesting rDNA product, although identity was not confirmed by sequencing. This non-specificity was found despite identities at primer sites and elsewhere within the known rDNA sequences being at levels below those thought tolerable for successful annealing, especially at the stringent temperatures (close to the primers $\mathrm{Tm}$ ) employed. The only other nested primer set targeting the rDNA of a fish-infecting microsporidian was developed by Barlough et al. (1995) for Nucleospora salmonis. This assay was also found to be nonspecific, with Nosema necatrix DNA giving a positive $\mathrm{PCR}$ signal. It is interesting to note that the non-target amplification obtained with the Nucleospora salmonis primers occurred with a Nosema Naegeli, 1857 species and not another fish-infecting microsporidian, as rDNA phylogenetic analyses have shown this intra-nuclear parasite to be distantly related to all other microsporidians, thus far sequenced, which infect fish (Nilsen et al. 1998, Bell et al. unpubl. data).

The Loma salmonae-specific primer set developed by Docker et al. (1997) was tested against Nucleospora salmonis (also known to infect chinook salmon), an unknown Microsporidium sp. from whitefish Prosopium williamsoni and L. embiotocia from the gills of shiner perch Cymatogaster aggregata. While the rRNA gene of $L$. salmonae shares little sequence identity with that of $N$. salmonis, it demonstrates more than $75 \%$ identity with the known rDNA sequences of both other test species. Indeed, L. salmonae and L. embiotocia possess $96.3 \%$ identity across 564 bp of rDNA. However, the 2 Loma Morrison \& Sprague, 1981 species exhibit quite different ITS regions, with the disparity within these
45 bp accounting for $70 \%$ of the total sequence variation. Consequently, these authors were able to successfully exploit this non-identity for one of their primers. Such levels of inter-specific variation within the ITS region do not exist between Microsporidium seriolae and the Microsporidium sp. parasitising red sea bream. These species were both found to demonstrate 2 forms of the rRNA gene, the shorter form in both cases having an $11 \mathrm{bp}$ deletion within the ITS region. As the longer form of the gene was never observed (from 5 sequenced clones) for the unidentified microsporidian from gilthead sea bream this region offers a potential target for discrimination. However, the occurrence of repetitive motifs within the ITS region of these microsporidians was thought to be responsible for the highly erratic behaviour of a primer set, designed in the current study, which incorporated an ITS-targeted primer. This set produced a 257 bp amplicon and was extremely sensitive (data not shown), as was that of Docker et al. (1997), which yielded a similar sized product but frequently amplified like-sized products from uninfected host DNA.

Due to sampling restrictions in the preliminary trial of the PCR assays, it was not possible to obtain a direct subsample of the homogenised yellowtail muscle to be examined by Uvitex $2 \mathrm{~B}$ staining for a parallel analysis by PCR; therefore the sensitivity of the 2 techniques could not be directly compared. However, even though the PCR analyses were performed on a twentieth of the muscle tissue used for Uvitex staining, the nested PCR was still able to detect a higher prevalence of infection (Table 2). The single PCR and Uvitex staining both revealed a $30 \%$ prevalence of infection, although the results were not congruent, with the identity of $50 \%$ of infected fish differing. Collectively these results may be explained by a combination of: the localised nature of infections and discrete tissue samples analysed by the 2 techniques, the presence of pre-spore forms, and differences in sensitivity. Uvitex $2 \mathrm{~B}$ staining revealed that fish Nos. 6 and 7 harboured mature spores, but even the nested PCR could not confirm this, probably due to the absence of infection in the PCR tissue samples. Nested PCR indicated that fish No. 15 was infected, as also demonstrated by Uvitex staining, whereas the single PCR was unable to detect infection in the PCR tissue sample. Fish Nos. 18, 19 and 20 tested positive for infection by both PCR assays, but not by Uvitex staining. In these cases it is likely that the presence of pre-spore forms accounts for the discrepancy. Since the initial report of Microsporidium seriolae infections in juvenile yellowtail (see Egusa 1982), challenges to newly stocked fish in the Kyushu region have continued yearly. Monitoring over an extended period has revealed no other microsporidian infections in these fish (Yokoyama et al. 1996, Sano et al. 1998, 
Yokoyama unpubl. data). Under such conditions the highly sensitive nested PCR may be used in preference to the single PCR assay for infection screening.

The transmission of fish-infecting microsporidia is thought to be direct with oral ingestion of spores the most likely entry route of the infective stage. Successful experimental infections have been performed by the addition of spores to tanks containing suitable host fish, the feeding of infected tissues, cohabitation of naive with infected fish, and intra-peritoneal and intramuscular injections (for review see Lom \& Dyková 1992, Shaw et al. 1998). However, on several different occasions Egusa (unpubl. data) failed in his attempts, by both feeding and immersion in-spore suspensions, to infect naive yellowtail with mature Microsporidium senriolae spores from naturally infected fish. Awakura (1974) was able to effect $M$. takedai transmission experimentally with fish derived spores, but considered it likely that plankton were involved, as an intermediate or paratenic host, in the natural transmission of this microsporidian to freshwater salmonids. It is possible that $M$. seriolae exhibits an indirect life-cycle akin to that found among the genera infecting mosquitoes/ copepods (see inter alia Andreadis 1985, Sweeney et al. 1990, Vossbrinck et al. 1998) and the PCR assays developed in the present study would provide invaluable tools for such investigations. In addition, these primer sets may be used to screen body fluids and tissues to determine the portals of entry and route of migration of $M$. seriolae to the musculature, findings that would probably enable a non-terminal sample to be used for early screening purposes.

Acknowledgements. The current study was performed during the tenure of a European Union (EU) / Japanese Society for the Promotion of Science (JSPS) research fellowship awarded to A.S.B. The authors would like to thank Dr Christina Sommerville of the Institute of Aquaculture, University of Stirling for the provision of Maltese material and Glugea sp. spores and Dr Tom Wiklund of AboAkademi University for Pleistophora mirandellae spores.

\section{LITERATURE CITED}

Abela M, Brinch-Iversen J, Tanti J, Brenton A (1996) Occurrence of a new histozoic microsporidian (Protozoa, Microspora) in cultured gilthead sea bream Sparus aurata L. Bull Eur Assoc Fish Pathol 16:196-199

Andreadis TG (1985) Experimental transmission of a microsporidian pathogen from mosquitoes to an alternate copepod host. Proc Natl Acad Sci USA 16:5574-5577

Awakura T (1974) Studies on the microsporidian infection in salmonid fishes. Sci Rep Hokkaido Fish Hatch 29:1-96

Barlough JE, McDowell TS, Milani A, Bigornia L, Slemenda SB, Pieniazek NJ, Hedrick RP (1995) Nested polymerase chain reaction for detection of Enterocytozoon salmonis genomic DNA in chinook salmon Onchorynchus tshawytscha. Dis Aquat Org 23:17-23
David F, Schuitema AR, Sarfati C, Liquory O, Hartskeerl RA, Derouin F, Molina JM (1996) Detection and species identification of intestinal microsporidia by PCR in duodenal biopsies from Human Immunodeficiency Virus-infected patients. J Infect Dis 174:874-877

DeGirolami PC, Ezratty CR, Desai G, McCullough G, Asmuth D, Wanke C, Federman M (1995) Diagnosis of intestinal microsporidiosis by examination of stool and duodenal aspirate with Weber's modified trichrome and Uvitex 213 stains. J Clin Microbiol 33:805-810

De Groote MA, Visvesvara GS, Wilson ML, Pieniazek NJ, Slemenda SB, Da Silva AJ, Leitch GJ, Bryan RT, Reves R (1995) Polymerase chain reaction and culture confirmation of disseminated Encephalitozoon cuniculi in a patient with AIDS: successful therapy with albendazole. J Infect Dis $171: 1375-1378$

Docker MF, Devlin RH, Richard J, Khattra J, Kent ML (1997) Sensitive and specific polymerase chain reaction assay for detection of Loma salmonae (Microsporea). Dis Aquat Org 29:41-48

Egusa S (1982) A microsporidian species from yellowtail juveniles, Seriola quinqueradiata, with 'Beko' disease. Fish Pathol 16:187-192 (in Japanese)

Egusa S, Hatai K, Fujimaki Y (1988) Notes on Microsporidium species, the etiological agent of 'Beko' disease in red sea bream juveniles, Pagrus major. Fish Pathol 23:263-267 (in Japanese)

Kent ML, Hervio DM, Docker MF, Devlin RH (1996). Taxonomy studies and diagnostic tests for myxosporean and microsporidian pathogens of salmonid fishes utilising ribosomal DNA sequence. J Eukaryot Microbiol 43: 98-99S

Lom J, Dyková I (1992) Microsporidia (Phylum Microspora Sprague, 1997). In: Developments in aquaculture and fisheries science, Vol 26. Protozoan parasites of fishes. Elsevier, Amsterdam, p 125-157

Nilsen F, Endresen C, Hordvik I (1998) Molecular phylogeny of microsporidians with particular reference to muscle infecting species of fishes. J Eukaryot Microbiol 45: $535-543$

Sano M. Sate J, Yokoyama H (1998) Occurrence of Beko disease caused by Microsporidium seriolae (Microspora) in hatchery-reared juvenile yellowtail. Fish Pathol 33:11-16

Schuitema ARJ, Hartskeerl RA, Van Gool T, Laxminarayan R, Terpstra WJ (1993) Application of the polymerase chain reaction for the diagnosis of microsporidiosis. AIDS 7:S57-61

Shaw RW, Kent ML, Adamson ML (1998) Modes of transmission of Loma salmonae (Microsporidia). Dis Aquat Org 19: $151-156$

Sweeney AW, Doggett SL, Piper RG (1990) Life cycle of Amblyospora indicola (Microspora: Amblyosporidae), a parasite of the mosquito Culex sitiens and of Apocyclops sp. copepods. J Invertebr Pathol 55:428-434

Visvesvara GS, Leitch GJ, Da Silva AJ, Croppo GP, Moura $H$, Wallace S, Slemenda SB, Schwartz DA, Moss D, Bryan RT, Pieniazek NJ (1994) Polyclonal and monoclonal antibody and PCR-amplification of small subunit rRNA identification of a microsporidian, Encephalitozoon hellem, isolated from an AIDS patient with disseminated infection. J Clin Microbiol 32:2760-2768

Vossbrinck CR, Baker MD, Didier ES, Debrunner-Vossbrinck BA, Shadduck JA (1993) Ribosomal DNA sequences of Encephalitozoon hellem and Encephalitozoon cuniculi: species identification and phylogenetic construction. J Eukaryot Microbiol 40:354-362

Vossbrinck CR, Andreadis TG, Debrunner-Vossbrinck BA 
(1998) Verification of intermediate hosts in the life cycles of microsporidia by small subunit rDNA sequencing. J Eukaryot Microbiol 45:290-292

Weiss LM, Vossbrinck CR (1998) Microsporidiosis: molecular and diagnostic aspects. Adv Parasitol 40:351-395

Yokoyama H, Kim JH, Sate J, Sane M, Hirano K (1996) Fluorochrome Uvitex 2B stain for detection of the micro-

Editorial responsibility: Wolfgang Körting,

Hannover, Germany sporidian causing Beko disease of yellowtail and goldstriped amberjack juveniles. Fish Pathol 31:99-104

Zhu X, Wittner M, Tanowitz HB, Call A, Weiss LM (1994) Ribosomal RNA sequences of Enterocytozoon bieneusi, Septata intestinalis and Ameson michaelis: phylogenetic construction and structural correspondence. J Eukaryot Microbiol 41:204-209

Submitted: January 4, 1999; Accepted: May 4, 1999 Proofs received from author(s): July 23, 1999 